\title{
Complete genome sequence of Thermobispora bispora type strain ( $\left(\mathrm{B} 51^{\mathrm{T}}\right)$
}

\author{
Konstantinos Liolios ${ }^{1}$, Johannes Sikorski ${ }^{2}$, Marlen Jando ${ }^{2}$, Alla Lapidus ${ }^{1}$, Alex Copeland ${ }^{1}$, \\ Tijana Glavina Del Rio ${ }^{1}$, Matt Nolan ${ }^{1}$, Susan Lucas ${ }^{1}$, Hope Tice', Jan-Fang Cheng ${ }^{1}$, Cliff \\ Han $^{1,3}$, Tanja Woyke1, Lynne Goodwin ${ }^{1,3}$, Sam Pitluck ${ }^{1}$, Natalia Ivanova ${ }^{1}$, Konstantinos \\ Mavromatis $^{1}$, Natalia Mikhailova ${ }^{1}$, Olga Chertkov ${ }^{1}$, Cheryl Kuske ${ }^{1}$, Amy Chen ${ }^{4}$, Krishna \\ Palaniappan $^{4}$, Miriam Land ${ }^{1,5}$, Loren Hauser ${ }^{1,5}$, Yun-Juan Chang ${ }^{1,5}$, Cynthia D. Jeffries ${ }^{1,5}$, John \\ C. Detter ${ }^{1,5}$, Thomas Brettin ${ }^{1,5}$, Manfred Rohde ${ }^{6}$, Markus Göker ${ }^{2}$, James Bristow ${ }^{1}$, Jonathan \\ A. Eisen ${ }^{1,7}$, Victor Markowitz ${ }^{4}$, Philip Hugenholtz ${ }^{1}$, Hans-Peter Klenk ${ }^{2}$, and Nikos C. \\ Kyrpides $^{1^{*}}$ \\ ${ }^{1}$ DOE Joint Genome Institute, Walnut Creek, California, USA \\ ${ }^{2}$ DSMZ - German Collection of Microorganisms and Cell Cultures GmbH, Braunschweig, \\ Germany \\ ${ }^{3}$ Los Alamos National Laboratory, Bioscience Division, Los Alamos, New Mexico, USA \\ ${ }^{4}$ Biological Data Management and Technology Center, Lawrence Berkeley National \\ Laboratory, Berkeley, California, USA \\ ${ }^{5}$ Oak Ridge National Laboratory, Oak Ridge, Tennessee, USA \\ ${ }^{6} \mathrm{HZI}$ - Helmholtz Centre for Infection Research, Braunschweig, Germany \\ ${ }^{7}$ University of California Davis Genome Center, Davis, California, USA
}

*Corresponding author: Nikos C. Kyrpides

Keywords: Two distinct 16S rRNA genes, strictly thermophilic, non-pathogenic, Streptosporangineae, GEBA

Thermobispora bispora (Henssen 1957) Wang et al. 1996 is the type species of the genus Thermobispora. This genus is of great interest because it is strictly thermophilic and because it has been shown for several of its members that the genome contains substantially distinct (6.4\% sequence difference) and transcriptionally active $16 \mathrm{~S}$ rRNA genes. Here we describe the features of this organism, together with the complete genome sequence and annotation. This is the second completed genome sequence of a member from the suborder Streptosporangineae and the first genome sequence of a member of the genus Thermobispora. The 4,189,976 bp long genome with its 3,596 protein-coding and 63 RNA genes is part of the Genomic Encyclopedia of Bacteria and Archaea project.

\section{Introduction}

Strain R51 ${ }^{\mathrm{T}}(=$ DSM $43833=$ ATCC $19993=\mathrm{JCM}$ $10125)$ is the type strain of the species Thermobispora bispora, which is the type species of the genus Thermobispora [1]. The generic name of the genus derives from the Greek words 'thermos', 'bis', and 'spora', to indicate high temperature two-spored organisms [1]. Strain R51 ${ }^{\mathrm{T}}$ was isolated from decaying manure in Berlin (Germany) in 1954 [2]. Other strains were isolated during the same research project from other types of manure in other cities in Germany and in Finland
[2]. As deduced from $16 \mathrm{~S}$ gene sequences, T. bispora was also found in compost in Sweden [3]. Historically, strain R51 ${ }^{\mathrm{T}}$ was originally classified in 1957 as Thermopolyspora bispora [2]. At the same time, a morphologically similar genus, $\mathrm{Mi}$ crobispora, was described [4], which has priority and $T$. bispora was subsequently transferred to the genus Microbispora [5,6]. However, based on thermal preferences $[2,7]$, chemotaxonomic features [7], and the two-dimensional polyacrylamide gel electrophoresis patterns of the ribo- 
somal protein AT-L30 [8], Microbispora bispora was subsequently removed from the genus $\mathrm{Mi}$ crobispora to be the type species of the new genus Thermobispora [1]. T. bispora is currently the only species in the genus Thermobispora [1]. In 1997 T. bispora gained interest, as it was described as the first organism to have two distinct (6.4\% of total nucleotides) types of transcriptionally active 16S rRNA genes (GenBank accessions U83909 and U83912) [9]. Based on the two copies of the 16S rRNA genes that match best to sequence U83909 the closest related type strain ( $9 \%$ sequence difference [10]) is Micromonospora pattaloongensis [11] of the family Micromonosporaceae; based on the two copies of the $16 \mathrm{~S}$ rRNA genes that match best to sequence U83912 the closest related type strain $(8 \%$ sequence difference [10]) is Planotetraspora silvatica [12] of the family Streptosporangiaceae. Neither fit to the taxonomic position as shown in the List of Procaryotic names with Standing in Nomenclature that shows the genus Thermobispora as a member of the family Pseudonocardiaceae, reflecting the current uncertainty of the taxonomic position of T. bispora [13]. In their recent review of Actinobacteria taxonomy, Zhi et al. [14] suggested to place Thermobispora in the suborder Streptosporangineae without assignment to a family, which is in accordance with our SSU rRNA tree (Figure 1). 16S rRNA sequences from environmental samples and metagenomic surveys with both $16 \mathrm{~S}$ rRNA sequences detected phylotypes with approximately $89-92 \%$ 16S rRNA gene sequence similarity to both (U83909 and U83912) reference sequences only in a compost metagenome [21], indicating a very rare occurrence of Thermobispora-spp. in the environment (status March 2010). Here we present a summary classification and a set of features for T. bispora $\mathrm{R} 51^{\mathrm{T}}$, together with the description of the complete genomic sequencing and annotation.

\section{Classification and features}

Figure 1 shows the phylogenetic neighborhood of for T. bispora $\mathrm{R} 51^{\mathrm{T}}$ in a $16 \mathrm{~S}$ rRNA based tree. The sequences of the four $16 \mathrm{~S}$ rRNA gene copies in the genome differ from each other by up to 94 nucleotides, and differ by up to 95 nucleotides from the previously published $16 \mathrm{~S}$ rRNA sequence generated from ATCC 19993 (U58523).

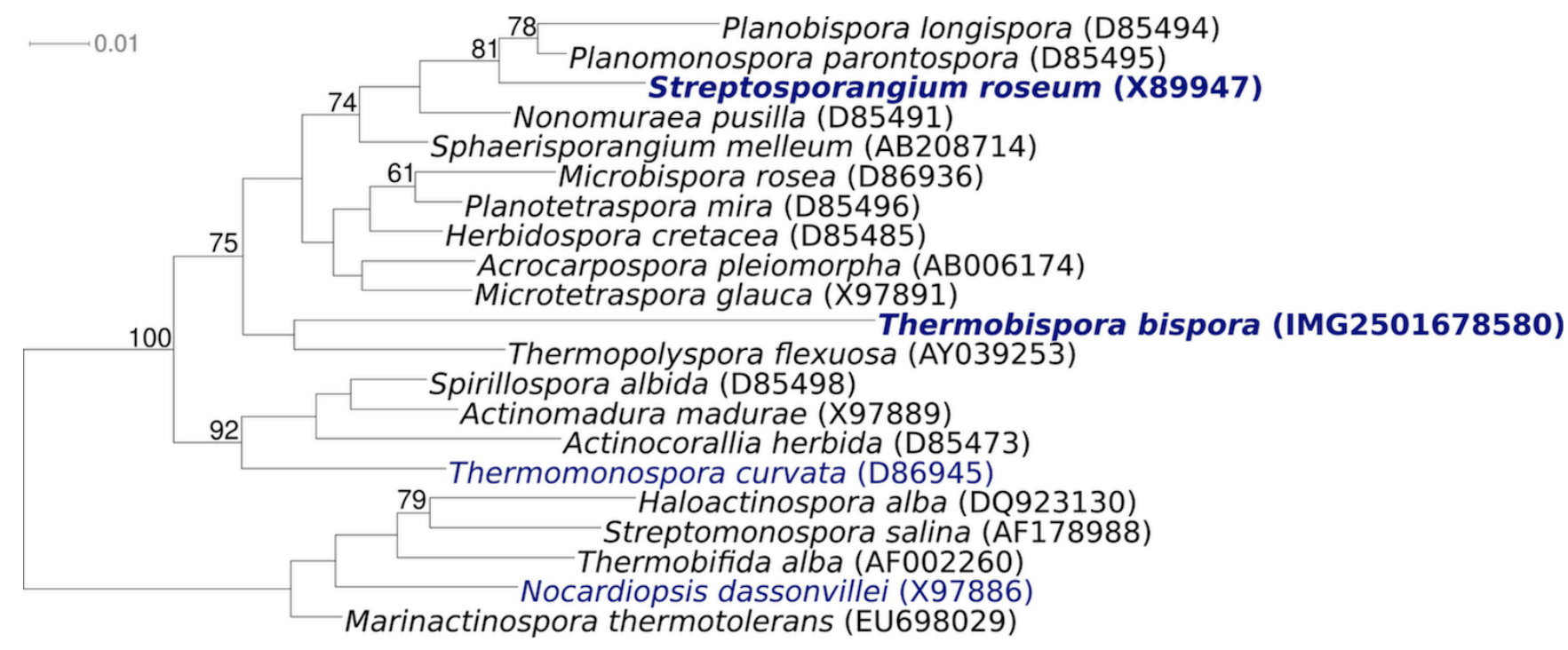

Figure 1. Phylogenetic tree highlighting the position of $T$. bispora $\mathrm{R} 51^{\top}$ relative to the type strains of the other genera within the suborder Streptosporangineae (except for Actinoallomurus, which was published after the analysis was completed). The tree was inferred from 1,371 aligned characters $[15,16]$ of the $16 \mathrm{~S}$ rRNA gene sequence under the maximum likelihood criterion [17] and rooted in accordance with the current taxonomy [18]. The branches are scaled in terms of the expected number of substitutions per site. Numbers above branches are support values from 1,000 bootstrap replicates if larger than $60 \%$. Lineages with type strain genome sequencing projects registered in GOLD [19] are shown in blue, published genomes in bold, e.g. the recently published GEBA genome from Streptosporangium roseum [20]. 
T. bispora cells form substrate mycelia whose hyphae are 0.5 to $0.8 \mu \mathrm{m}$ in diameter [1] (Figure 2). The aerial mycelia branch monopodally and bear longitudinal pairs of spores [1] (not visible in Figure 2). The spore diameters are usually 1.2 to 2.0 $\mu \mathrm{m}$, but in liquid media spores with a diameter of $3 \mu \mathrm{m}$ may occur [1]. The aerial mycelia are white, and the substrate mycelia are yellow or yellowish brown on the media used in the respective study (International Streptomyces Project medium 4 agar and IF0328 agar; Institute for Fermentation) [1]. No soluble pigment is produced [1]. T. bispora is an obligately thermophilic organism (Table 1) [1]. Starch is not hydrolyzed; inositol and rhamnose are utilized for growth, but arabinose and glycerol are not utilized [1]. Also, T. bispora is negative for iodinin production and nitrate reduction [1].

\section{Chemotaxonomy}

The cell wall of strain $\mathrm{R} 51^{\mathrm{T}}$ contains predominantly the menaquinone MK- $9\left(\mathrm{H}_{0}\right)(75 \%)$ and only small amounts of MK-9 $\left(\mathrm{H}_{2}\right)$ and $\mathrm{MK}-9\left(\mathrm{H}_{4}\right)$ [7]. Strain $\mathrm{R} 51^{\mathrm{T}}$ has a type PIV phospholipid pattern, and contains phosphatidylethanolamine but not phosphatidylglycerol and trace amounts of glucosamine-containing phospholipids [7]. The cell wall contains a major amount of meso-diaminopimelic acid, and the whole-cell hydrolysate contains madurose and galactose [1]. The fatty acid composition of strain $\mathrm{R} 51^{\mathrm{T}}$ is dominated by saturated acids, with iso- $\mathrm{C}_{16: 0}(55 \%)$ being the most frequent acid, followed by anteiso- $\mathrm{C}_{17: 0}(8 \%)$, the unsaturated $\mathrm{C}_{18: 1}(8 \%)$, iso- $\mathrm{C}_{18: 0}(6 \%)$ and $\mathrm{C}_{16: 0}$ [7]. Also, strain $\mathrm{R} 51^{\mathrm{T}}$ contains minor amounts of 10 -methylbranched chain fatty acids [7].

\section{Genome sequencing and annotation Genome project history}

This organism was selected for sequencing on the basis of its phylogenetic position [27], and is part of the Genomic Encyclopedia of Bacteria and Archaea project [28]. The genome project is deposited in the Genome OnLine Database [19] and the complete genome sequence is deposited in GenBank. Sequencing, finishing and annotation were performed by the DOE Joint Genome Institute (JGI). A summary of the project information is shown in Table 2.

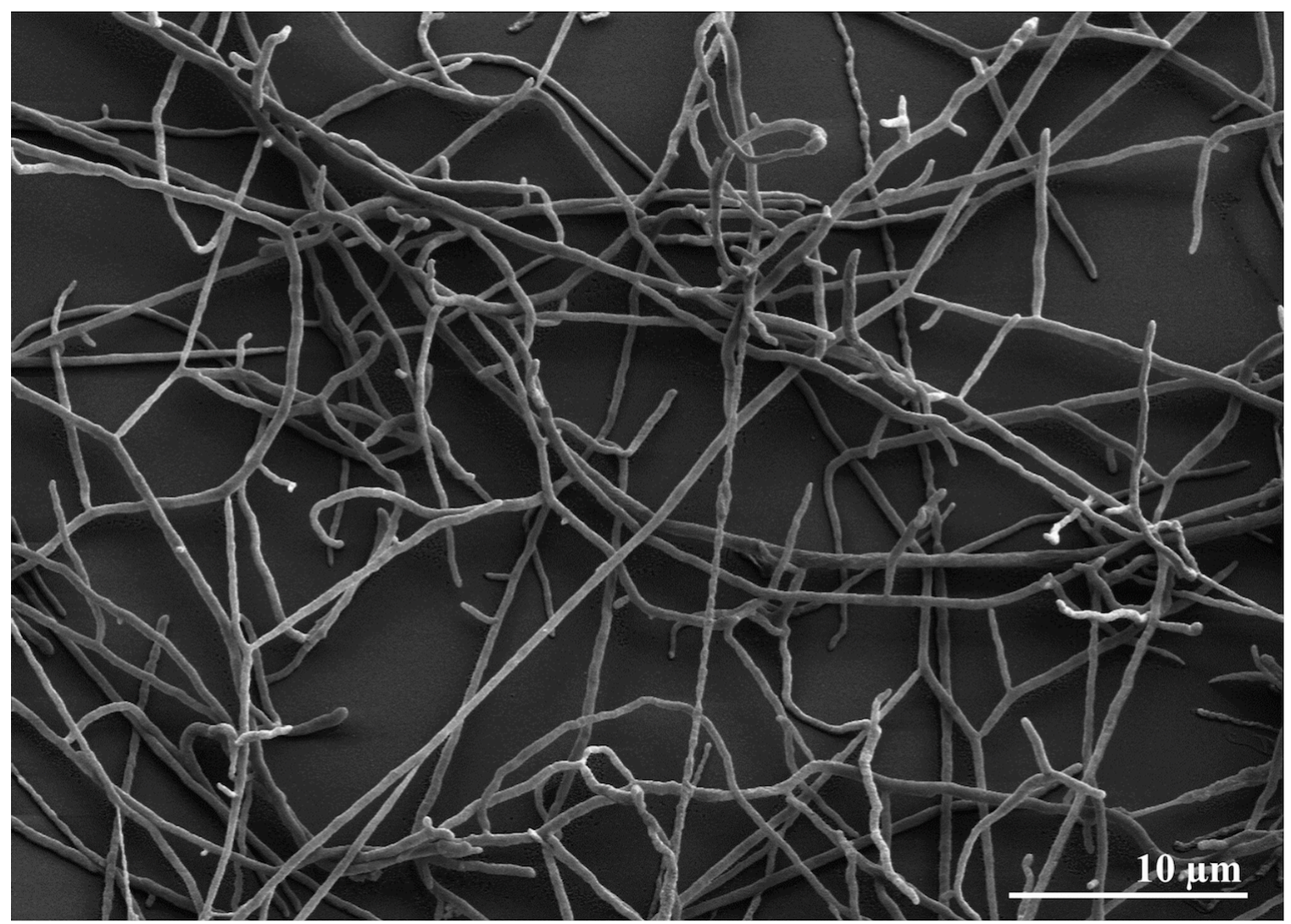

Figure 2. Scanning electron micrograph of T. bispora $\mathrm{R} 51^{\mathrm{T}}$ 
Table 1. Classification and general features of T. bispora $\mathrm{R} 51^{\top}$ according to the MIGS recommendations [22]

\begin{tabular}{|c|c|c|c|}
\hline MIGS ID & Property & Term & Evidence code \\
\hline & \multirow{10}{*}{ Current classification } & Domain Bacteria & TAS [23] \\
\hline & & Phylum 'Actinobacteria' & TAS [13] \\
\hline & & Class Actinobacteria & TAS [24] \\
\hline & & Subclass Actinobacteridae & TAS $[14,24]$ \\
\hline & & Order Actinomycetales & TAS [14] \\
\hline & & Suborder Streptosporangineae & TAS [14] \\
\hline & & Family Incertae sedis & TAS [14] \\
\hline & & Genus Thermobispora & TAS [1] \\
\hline & & Species Thermobispora bispora & TAS [2] \\
\hline & & Type strain R51 & TAS [5] \\
\hline & Gram stain & positive & TAS [1] \\
\hline & Cell shape & mycelia with hyphae & TAS [2] \\
\hline & Motility & non-motile & TAS [1] \\
\hline & Sporulation & sporulating & TAS [1] \\
\hline & Temperature range & thermophile, $50^{\circ} \mathrm{C}-65^{\circ} \mathrm{C}$ & TAS [1] \\
\hline & Optimum temperature & not determined & TAS [1] \\
\hline & Salinity & not determined & TAS [1] \\
\hline \multirow[t]{3}{*}{ MIGS-22 } & Oxygen requirement & aerobic & TAS $[1,2]$ \\
\hline & Carbon source & inositol and rhamnose & TAS [1] \\
\hline & Energy source & sugars & TAS [1] \\
\hline MIGS-6 & Habitat & compost and other decaying material & TAS $[2,3]$ \\
\hline MIGS-15 & Biotic relationship & unknown & \\
\hline \multirow[t]{3}{*}{ MIGS-14 } & Pathogenicity & not reported & \\
\hline & Biosafety level & 1 & TAS [25] \\
\hline & Isolation & decaying mixed manure & TAS [2] \\
\hline MIGS-4 & Geographic location & Berlin, Germany & TAS [2] \\
\hline MIGS-5 & Sample collection time & September 30, 1954 & TAS [2] \\
\hline MIGS-4.1 & Latitude & 52.52 & NAS \\
\hline MIGS-4.2 & Longitude & 14.42 & NAS \\
\hline MIGS-4.3 & Depth & not reported & \\
\hline MIGS-4.4 & Altitude & not reported & \\
\hline
\end{tabular}

Evidence codes - IDA: Inferred from Direct Assay (first time in publication); TAS: Traceable Author Statement (i.e., a direct report exists in the literature); NAS: Non-traceable Author Statement (i.e., not directly observed for the living, isolated sample, but based on a generally accepted property for the species, or anecdotal evidence). These evidence codes are from of the Gene Ontology project [26]. If the evidence code is IDA, then the property was directly observed for a live isolate by one of the authors or an expert mentioned in the acknowledgements.

\section{Growth conditions and DNA isolation}

T. bispora strain R51 ${ }^{\mathrm{T}}$, DSM 43833, was grown in DSMZ medium 84 (Rolled oats mineral medium) [29] at $55^{\circ} \mathrm{C}$. DNA was isolated from 1-1.5 g of cell paste using Qiagen Genomic 500 DNA Kit (Qiagen, Hilden, Germany) with lysis modification st/FT according to Wu et al. [28].

\section{Genome sequencing and assembly}

The genome of $T$. bispora was sequenced using a combination of Sanger and 454 sequencing platforms. All general aspects of library construction and sequencing can be found at http://www.jgi.doe.gov/. 454 pyrosequencing reads were assembled using the Newbler assembler version 1.1.02.15 (Roche). Large Newbler contigs were broken into 4,798 
overlapping fragments of $1,000 \mathrm{bp}$ and entered into assembly as pseudo-reads. The sequences were assigned quality scores based on Newbler consensus q-scores with modifications to account for overlap redundancy and to adjust inflated qscores. A hybrid 454/Sanger assembly was made using the parallel phrap assembler (High Performance Software, LLC). Possible mis-assemblies were corrected with Dupfinisher or transposon bombing of bridging clones [30]. Gaps between contigs were closed by editing in Consed, custom primer walk or PCR amplification. A total of 1,181 Sanger finishing reads were produced to close gaps, to resolve repetitive regions, and to raise the quality of the finished sequence. The error rate of the completed genome sequence is less than 1 in 100,000 . The final assembly consists of 40,290 Sanger and $1.1 \times$ pyrosequence based pseudoreads. Together Sanger reads and pseudo-reads provided $8.19 \times$ coverage of the genome.

Table 2. Genome sequencing project information

\begin{tabular}{lll}
\hline MIGS ID & Property & Term \\
\hline MIGS-31 & Finishing quality & $\begin{array}{l}\text { Finished } \\
\text { Three genomic libraries: } \\
\text { two Sanger libraries }-8 \mathrm{~kb} \text { pMCL200 and fosmid } \\
\text { pcc1FOS and one 454 pyrosequece standard library }\end{array}$ \\
LIGS-28 & Libraries used & ABI3730, 454 GS FLX \\
MIGS-29 & Sequencing platforms & N.1× Sanger; 1.1× pyrosequence pseudo-reads \\
MIGS-31.2 & Sequencing coverage & Newbler version 1.1.02.15, phrap \\
MIGS-30 & Assemblers & Prodigal, GenePRIMP \\
MIGS-32 & Gene calling method & CP001874 \\
& INSDC ID & May 17, 2010 \\
& Genbank Date of Release & Gc01281 \\
& GOLD ID & 469371 \\
& NCBI project ID & 2501651196 \\
& Database: IMG-GEBA & DSM 43833 \\
MIGS-13 & Source material identifier & Tree of Life, GEBA \\
& Project relevance &
\end{tabular}

Table 3. Genome Statistics

\begin{tabular}{lrr}
\hline Attribute & Value & \% of Total \\
\hline Genome size (bp) & $4,189,976$ & $100.00 \%$ \\
DNA coding region (bp) & $3,548,135$ & $84.68 \%$ \\
DNA G+C content (bp) & $3,034,765$ & $72.43 \%$ \\
Number of replicons & 1 & \\
Extrachromosomal elements & 0 & \\
Total genes & 3,659 & $100.00 \%$ \\
RNA genes & 63 & $1.72 \%$ \\
rRNA operons & 3 & \\
Protein-coding genes & 3,596 & $98.28 \%$ \\
Pseudo genes & 50 & $1.37 \%$ \\
Genes with function prediction & 2,632 & $71.93 \%$ \\
Genes in paralog clusters & 491 & $13.42 \%$ \\
Genes assigned to COGs & 2,610 & $71.33 \%$ \\
Genes assigned Pfam domains & 2,844 & $77.73 \%$ \\
Genes with signal peptides & 795 & $21.73 \%$ \\
Genes with transmembrane helices & 864 & $23.61 \%$ \\
CRISPR repeats & 6 & \\
\hline
\end{tabular}




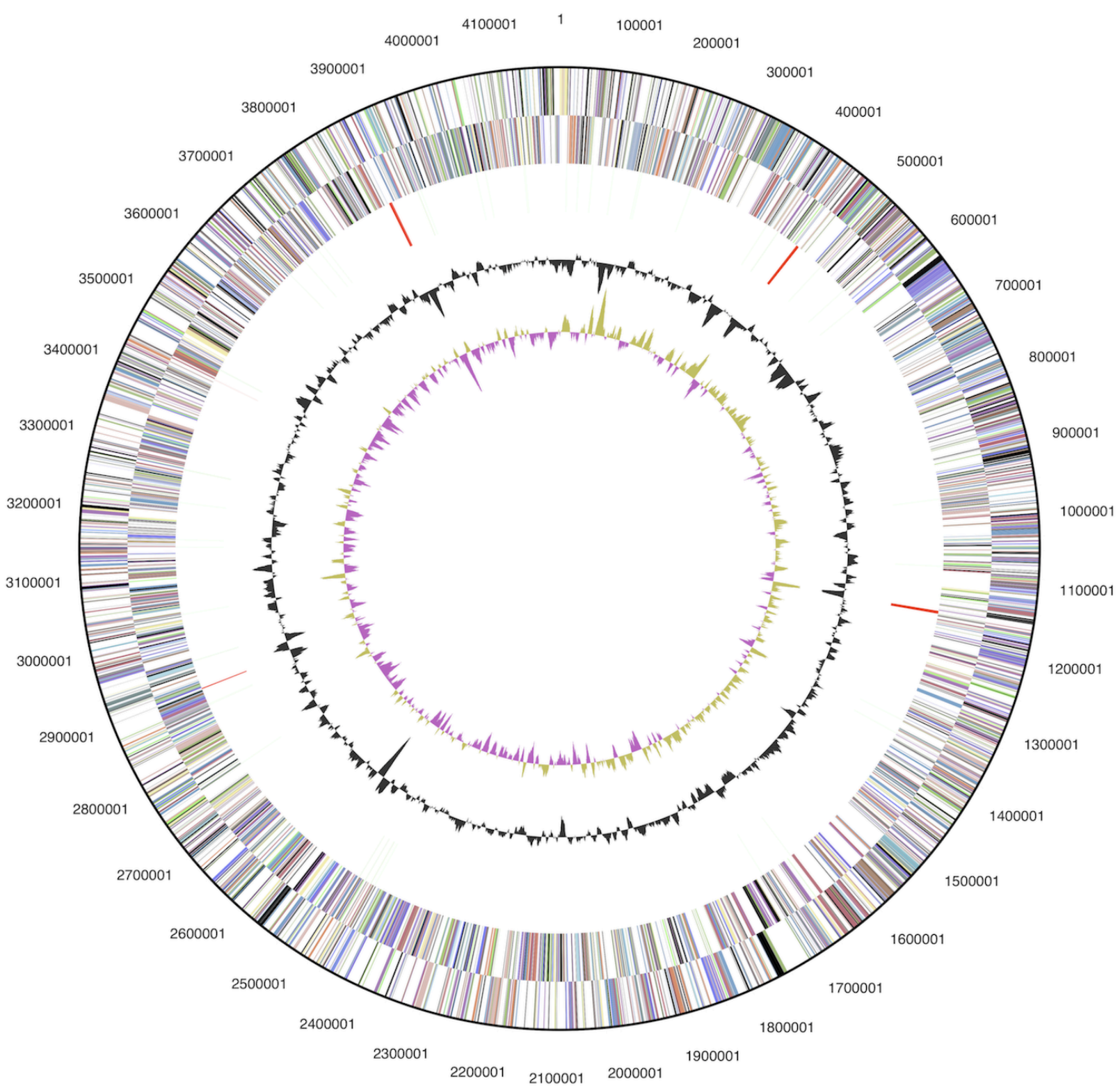

Figure 3. Graphical circular map of the genome. From outside to the center: Genes on forward strand (color by COG categories), Genes on reverse strand (color by COG categories), RNA genes (tRNAs green, rRNAs red, other RNAs black), GC content, GC skew.

\section{Genome annotation}

Genes were identified using Prodigal [31] as part of the Oak Ridge National Laboratory genome annotation pipeline, followed by a round of manual curation using the JGI GenePRIMP pipeline [32]. The predicted CDSs were translated and used to search the National Center for Biotechnology Information (NCBI) nonredundant database, UniProt, TIGRFam, Pfam, PRIAM, KEGG, COG, and InterPro databases. Additional gene prediction analysis and manual functional annotation was performed within the Integrated Microbial Genomes Expert Review (IMG-ER) platform [33].

\section{Genome properties}

The genome is 4,189,976 bp long and comprises one main circular chromosome with an overall GC content of $72.4 \%$ (Table 3 and Figure 3). Of the 3,659 genes predicted, 3,596 were protein-coding genes, and 63 RNAs; fifty pseudogenes were also identified. The majority of the protein-coding genes $(71.9 \%)$ were assigned with a putative function while the remaining ones were annotated as hypothetical proteins. The distribution of genes into COGs functional categories is presented in Table 4. 
Table 4. Number of genes associated with the general COG functional categories

\begin{tabular}{lrrl}
\hline Code & value & \%age & Description \\
\hline J & 149 & 5.0 & Translation, ribosomal structure and biogenesis \\
A & 1 & 0.0 & RNA processing and modification \\
K & 304 & 10.3 & Transcription \\
L & 141 & 4.8 & Replication, recombination and repair \\
B & 1 & 0.0 & Chromatin structure and dynamics \\
D & 21 & 1.0 & Cell cycle control, cell division, chromosome partitioning \\
Y & 0 & 0.0 & Nuclear structure \\
V & 48 & 1.6 & Defense mechanisms \\
T & 192 & 6.5 & Signal transduction mechanisms \\
M & 140 & 4.7 & Cell wall/membrane biogenesis \\
N & 3 & 0.1 & Cell motility \\
Z & 0 & 0.0 & Cytoskeleton \\
W & 0 & 0.0 & Extracellular structures \\
U & 29 & 1.0 & Intracellular trafficking, secretion, and vesicular transport \\
O & 98 & 3.3 & Posttranslational modification, protein turnover, chaperones \\
C & 204 & 6.9 & Energy production and conversion \\
G & 221 & 7.5 & Carbohydrate transport and metabolism \\
E & 279 & 9.4 & Amino acid transport and metabolism \\
F & 82 & 2.8 & Nucleotide transport and metabolism \\
H & 146 & 4.9 & Coenzyme transport and metabolism \\
I & 133 & 4.5 & Lipid transport and metabolism \\
P & 138 & 4.7 & Inorganic ion transport and metabolism \\
Q & 85 & 2.9 & Secondary metabolites biosynthesis, transport and catabolism \\
R & 351 & 11.9 & General function prediction only \\
S & 191 & 6.5 & Function unknown \\
- & 1,049 & 28.7 & Not in COGs \\
\hline & & & \\
\hline
\end{tabular}

\section{Acknowledgements}

We would like to gratefully acknowledge the help of Susanne Schneider (DSMZ) for DNA extraction and quality analysis. This work was performed under the auspices of the US Department of Energy Office of Science, Biological and Environmental Research Program, and by the University of California, Lawrence Berkeley National Laboratory under contract No. DE-

\section{References}

1. Wang Y, Zhang Z, Ruan J. A proposal to transfer Microbispora bispora (Lechevalier 1965) to a new genus, Thermobispora gen. nov., as Thermobispora bispora comb. nov. Int / Syst Bacteriol 1996;

46:933-938. PubMed doi:10.1099/00207713-46$\underline{4-933}$
AC02-05CH11231, Lawrence Livermore National Laboratory under Contract No. DE-AC52-07NA27344, Los Alamos National Laboratory under contract No. DEAC02-06NA25396, and Oak Ridge National Laboratory under contract DE-AC05-000R22725, as well as German Research Foundation (DFG) INST 599/1-1 and SI 1352/1-2.
2. Henssen A. Beiträge zur Morphologie und Systematik der thermophilen Actinomyceten. Arch Microbiol 1957; 26:373-414. doi:10.1007/BF00407588

3. Steger K, Jarvis A, Vasara T, Romantschuk M, Sundh I. Effects of differing temperature manage- 
ment on development of Actinobacteria populations during composting. Res Microbiol 2007;

158:617-624. PubMed doi:10.1016/j.resmic.2007.05.006

4. Nonomura $\mathrm{H}$, Ohara I. On a new actinomycete, Microbispora, isolated from soil. Abstract 98, pages 31 and 32, Abstracts of papers presented at the annual meeting of the Agricultural Chemical Society of Japan. Tokyo University, April 9th to Ilth, 1957. Published by the Agricultural Chemical Society (in Japanese). 1957.

5. Henssen A, Schnepf E. Zur Kenntnis thermophiler Actinomyceten. Arch Microbiol 1967; 57:214231. doi:10.1007/BF00405948

6. Lechevalier HA. Priority of the generic name Microbispora over Waksmania and Thermopolyspora. Int Bull Bacteriol Nomencl Taxon 1965; 15:139-142. doi:10.1099/00207713-15-3-139

7. Miyadoh S, Amano S, Tohyama H, Shomura T. A taxonomic review of the genus Microbispora and a proposal to transfer two species to the genus Actinomadura and to combine ten species into $\mathrm{Mi}$ crobispora rosea. J Gen Microbiol 1990;

136:1905-1913. PubMed

8. Ochi K, Haraguchi K, Miyadoh S. A taxonomic review of the genus Microbispora by analysis of ribosomal protein AT-L30. Int / Syst Bacteriol 1993; 43:58-62. PubMed doi:10.1099/0020771343-1-58

9. Wang Y, Zhang Z, Ramanan N. The actinomycete Thermobispora bispora contains two distinct types of transcriptionally active $16 \mathrm{~S}$ rRNA genes. I Bacteriol 1997; 179:3270-3276. $\underline{\text { PubMed }}$

10. Chun J, Lee JH, Jung Y, Kim M, Kim S, Kim BK, Lim YW. EzTaxon: a web-based tool for the identification of prokaryotes based on 16S ribosomal RNA gene sequences. Int / Syst Evol Microbiol 2007; 57:2259-2261. PubMed doi:10.1099/ijs.0.64915-0

11. Thawai C, Tanasupawat S, Kudo T. Micromonospora pattaloongensis sp. nov., isolated from Thai mangrove forest. Int I Syst Evol Microbiol 2008; 58:1516-1521. PubMed doi:10.1099/ijs.0.65410$\underline{0}$

12. Tamura T, Sakane T. Planotetraspora silvatica sp. nov., and emended description of the genus Planotetraspora. Int I Syst Evol Microbiol 2004; 54:2053-2056. PubMed doi:10.1099/ijs.0.02981$\underline{0}$

13. Garrity GM, Holt JG. The Road Map to the Manual. In: Garrity GM, Boone DR, Castenholz RW (eds), Bergey's Manual of Systematic Bacteriolo- gy, Second Edition, Volume 1, Springer, New York, 2001, p. 119-169.

14. Zhi XY, Li WJ, Stackebrandt E. An update of the structure and $16 \mathrm{~S}$ rRNA gene sequence-based definition of higher ranks of the class Actinobacteria, with the proposal of two new suborders and four new families and emended descriptions of the existing higher taxa. Int / Syst Evol Microbiol 2009; 59:589-608. PubMed doi:10.1099/ijs.0.65780-0

15. Castresana J. Selection of conserved blocks from multiple alignments for their use in phylogenetic analysis. Mol Biol Evol 2000; 17:540-552. PubMed

16. Lee C, Grasso C, Sharlow MF. Multiple sequence alignment using partial order graphs. BioinformatiCs 2002; 18:452-464. PubMed doi:10.1093/bioinformatics/18.3.452

17. Stamatakis A, Hoover P, Rougemont J. A rapid bootstrap algorithm for the RAxML web servers. Syst Biol 2008; 57:758-771. PubMed doi:10.1080/10635150802429642

18. Yarza P, Richter M, Peplies J, Euzeby JP, Amann R, Schleifer KH, Ludwig W, Glöckner FO, Rossello-Mora R. The All-Species Living Tree project: A $16 \mathrm{~S}$ rRNA-based phylogenetic tree of all sequenced type strains. Syst Appl Microbiol 2008; 31:241-250. PubMed doi:10.1016/j.syapm.2008.07.001

19. Liolios K, Chen IM, Mavromatis K, Tavernarakis N, Hugenholtz P, Markowitz VM, Kyrpides NC. The Genomes On Line Database (GOLD) in 2009: status of genomic and metagenomic projects and their associated metadata. Nucleic Acids Res 2010; 38:D346-D354. PubMed doi:10.1093/nar/gkp848

20. Nolan M, Sikorski J, Jando M, Lucas S, Lapidus A, Glavina Del Rio T, Chen F, Tice H, Pitlick S, Cheng JF, et al. Complete genome sequence of Streptosporangium roseum type strain $\left(\mathrm{NI} \mathrm{9100}{ }^{\top}\right.$ ). Stand Genomic Sci 2010; 2:29-37. doi:10.4056/sigs.631049

21. Allgaier M, Reddy A, Park JI, Ivanova N, D'haeseleer P, Lowry S, Sapra R, Hazen TC, Simmons BA, VanderGheynst JS et al. Targeted discovery of glycoside hydrolases from a switchgrass-adapted compost community. PLOS ONE 2010; 5:e8812. $\underline{\text { PubMed doi:10.1371/journal.pone.0008812 }}$

22. Field D, Garrity G, Gray T, Morrison N, Selengut J, Sterk P, Tatusova T, Thomson N, Allen MJ, Angiuoli $S V$, et al. The minimum information about a genome sequence (MIGS) specification. Nat 
Biotechnol 2008; 26:541-547. PubMed

doi:10.1038/nbt1360

23. Woese CR, Kandler O, Wheelis ML. Towards a natural system of organisms: proposal for the domains Archaea, Bacteria, and Eucarya. Proc Natl Acad Sci USA 1990; 87:4576-4579. PubMed doi:10.1073/pnas.87.12.4576

24. Stackebrandt E, Rainey FA, Ward-Rainey NL. Proposal for a new hierarchic classification system, Actinobacteria classis nov. Int / Syst Bacteriol 1997; 47:479-491. doi:10.1099/00207713-47-2$\underline{479}$

25. Classification of bacteria and archaea in risk groups. http://www.baua.de TRBA 466.

26. Ashburner M, Ball CA, Blake JA, Botstein D, Butler $\mathrm{H}$, Cherry JM, Davis AP, Dolinski K, Dwight SS, Eppig JT, et al. Gene Ontology: tool for the unification of biology. Nat Genet 2000; 25:25-29. $\underline{\text { PubMed doi:10.1038/75556 }}$

27. Klenk HP, Göker M. En route to a genome-based classification of Archaea and Bacteria? Syst Appl Microbiol 2010; 33:175-182. PubMed doi:10.1016/j.syapm.2010.03.003

28. Wu D, Hugenholtz P, Mavromatis K, Pukall R, Dalin E, Ivanova NN, Kunin V, Goodwin L, Wu $M$, Tindall BJ, et al. A phylogeny-driven genomic encyclopaedia of Bacteria and Archaea. Nature 2009; 462:1056-1060. PubMed doi:10.1038/nature08656

29. List of growth media used at DSMZ: http://www.dsmz.de/microorganisms/media_list.p hp.

30. Sims D, Brettin T, Detter J, Han C, Lapidus A, Copeland A, Glavina Del Rio T, Nolan M, Chen F, Lucas $\mathrm{S}$, et al. Complete genome sequence of $\mathrm{Ky}$ tococcus sedentarius type strain $\left(541^{\top}\right)$. Stand Genomic Sci 2009; 1:12-20. doi:10.4056/sigs.761

31. Hyatt D, Chen GL, LoCascio PF, Land ML, Larimer FW, Hauser LJ. Prodigal: prokaryotic gene recognition and translation initiation site identification. Bioinformatics 2010; 11:119. PubMed doi:10.1186/1471-2105-11-119

32. Pati A, Ivanova N, Mikhailova N, Ovchinikova G, Hooper SD, Lykidis A, Kyrpides NC. GenePRIMP: A gene prediction improvement ipeline for microbial genomes. Nat Methods 2010; 7:455-457. PubMed doi:10.1038/nmeth.1457

33. Markowitz VM, Ivanova NN, Chen IMA, Chu K, Kyrpides NC. IMG ER: a system for microbial genome annotation expert review and curation. Bioinformatics 2009; 25:2271-2278. PubMed doi:10.1093/bioinformatics/btp393 